\title{
Highly efficient methods for the one-pot synthesis of $\beta$-substituted enones
}

\author{
William J. Kerr, * Colin M. Pearson and Graeme J. Thurston
}

\author{
Received 30th August 2005, Accepted 3rd November 2005 \\ First published as an Advance Article on the web 25th November 2005 \\ DOI: $10.1039 / b 512177$ a
}

\begin{abstract}
A mild and practically-convenient one-pot procedure for the direct $\beta$-substitution of enones has been developed using a conjugate addition-oxidation strategy with a full range of copper-based reagents and $N$-tert-butylphenylsulfinimidoyl chloride; alkyl- and aryl-substituted enones are delivered in good to excellent yields.
\end{abstract}

$\beta$-Functionalised enones are of elevated importance in organic chemistry and have wide preparative utility in transformations such as Michael addition processes and Diels-Alder reactions. Having stated this, synthetic methods for the production of this moiety are somewhat limited. Although effective preparative strategies exist, in general, most techniques involve multistage processes, harsh reaction conditions, or the use of expensive transition metals. In this regard, perhaps the most widely used method for the formation of $\beta$-substituted enones is based on the conjugate addition of an alkyl or aryl cuprate to an enone, followed by the introduction of a selenyl species to provide an $\alpha$-arylselenyl ketone, which can then be oxidised and eliminated. ${ }^{1}$ Despite the efficacy of this strategy, the toxicity and two-step nature of the process somewhat detract from its synthetic utility. The analogous technique with a substituted sulfide ${ }^{2}$ also has severe limitations with regard to functional group compatibility, given the relatively harsh reaction conditions required for the oxidation/elimination. Another applicable method for enone functionalisation is the use of $\beta$-halo enones which, following 1,4-addition, readily eliminate to generate the substituted enone product. ${ }^{3}$ Although valuable, the difficulty in accessing $\beta$-halo enones and the formation of disubstituted by-products, limit the utility of this methodology severely. More recently, Nicolaou ${ }^{4}$ and co-workers have reported on the use of IBX to generate $\beta$-substituted enones in an efficient manner, from $\beta$-substituted trimethylsilyl enol ethers, themselves generated by conjugate addition to enones. Although this methodology is very mild and efficient, it again involves a multistep process.

In 2000, Mukaiyama and co-workers reported on the use of the versatile reagent, $N$-tert-butylphenylsulfinimidoyl chloride (1) ${ }^{5}$ as an oxidant which mediated the oxidation (dehydrogenation) of a series of organic compounds. ${ }^{6,7}$ In particular, this reagent can be employed in the oxidation of alcohols, amines, and hydroxylamines, ${ }^{7}$ and in the dehydrogenation of ketones to enones under very mild, low temperature conditions. ${ }^{6 b, 8}$ In attempts to further widen the applicability of this sulfinimidoyl species, and given the commercial availability ${ }^{9}$ and relative ease of preparation of 1 on a large scale ${ }^{5 b}$ we believed that this reagent could be strategically utilised in a novel fashion to directly access $\beta$-substituted enones. More specifically and as illustrated in Scheme 1, we envisaged

WestCHEM, Department of Pure and Applied Chemistry, University of Strathclyde, 295 Cathedral Street, Glasgow, Scotland, UK G1 1XL. Email:w.kerr@strath.ac.uk; Fax: +44 141548 4246; Tel: +44 1415482959

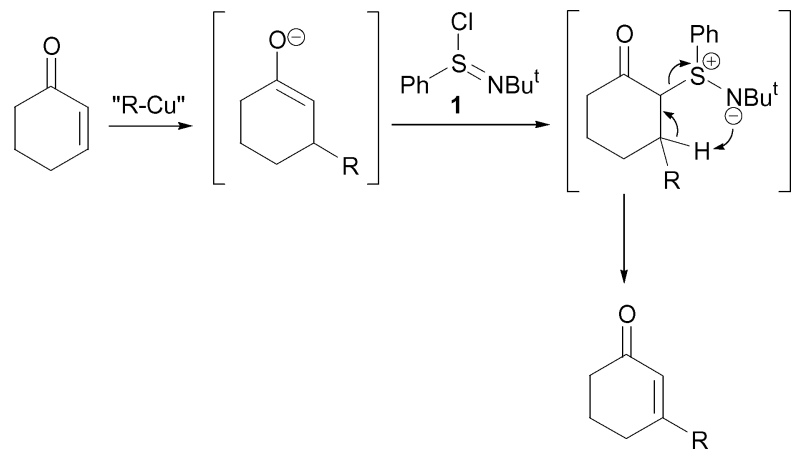

Scheme 1

that, following conjugate addition of an organocuprate to an $\alpha, \beta$-unsaturated enone, $N$-tert-butylphenylsulfinimidoyl chloride (1) could be applied as an electrophilic quench to generate $\beta$ substituted enones directly from unsubstituted enones in a onepot, two-step procedure. Accordingly, this strategy was embarked upon. However, following completion of our studies and during the preparation of our manuscript for publication, Matsuo and Aizawa divulged their findings using a very similar approach. ${ }^{10}$ Based on this, we now communicate the preparative outcomes from our endeavours in this area, whilst highlighting the differences and potentially wider practical utility of our techniques over the recently published procedures.

Based on the utility and synthetic complementarity of the range of known organocuprate reagents and protocols, ${ }^{11}$ we felt that any procedure that was developed as part of this programme should be compatible with as wide a spectrum of the available copper-based methods as possible. Nonetheless, to initiate our studies in this area, we investigated the reaction of a simple Gilman cuprate, ${ }^{12}$ lithium di- $n$-butylcuprate, with cyclohex-2-enone, followed by application of $\mathbf{1}$ as the electrophilic quench. As shown in Table 1, Entry 1, using 2.5 equivalents of $N$-tert-butylphenylsulfinimidoyl chloride (1), the desired one-pot transformation was found to be achievable, albeit in a rather low 39\% yield. In order to optimise the efficiency of this process, the number of equivalents of 1 was progressively increased. Gratifyingly, an improved yield was obtained following each increase in the quantity of the sulfinimidoyl chloride employed. Indeed, using 5 equivalents of 1 produced a good yield of $82 \%$ of the desired $\beta$-substituted enone product (Table 1, Entry 4). Importantly, at this stage, we felt that to enhance the reactivity of the intermediate enolate ion, formed following conjugate addition, tuning of the polarity of the reaction medium could be beneficial. Accordingly, the oxidant 1 was added in the more polar THF. When this practical amendment was made, the two-step, one-pot addition-oxidative quench was achieved in an excellent and near quantitative 98\% yield (Table 1, Entry 5). Consequently, following this brief programme of optimisation, by 
Table 1 Optimisation of the one-pot $\beta$-substitution of cyclohex-2-enone with a simple Gilman cuprate

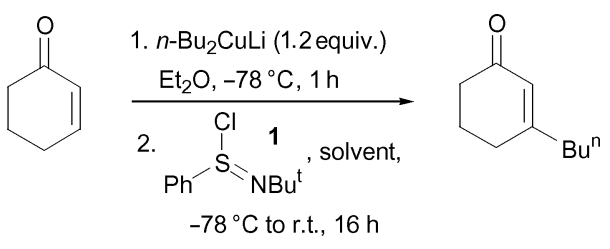

\begin{tabular}{llll}
\hline Entry & Solvent $^{a}$ & $\mathbf{1}$ (equiv.) & Yield $(\%)^{b}$ \\
\hline 1 & $\mathrm{Et}_{2} \mathrm{O}$ & 2.5 & 39 \\
2 & $\mathrm{Et}_{2} \mathrm{O}$ & 3.2 & 59 \\
3 & $\mathrm{Et}_{2} \mathrm{O}$ & 4.4 & 67 \\
4 & $\mathrm{Et}_{2} \mathrm{O}$ & 5.0 & 82 \\
5 & $\mathrm{THF}$ & 5.0 & 98
\end{tabular}

${ }^{a}$ Solvent used for the addition of $1 .{ }^{b}$ Isolated yield.

employing readily prepared and handled simple cuprate reagents, followed by sulfinimidoyl chloride (1), a practically-convenient protocol had been established for the direct preparation of $\beta$ substituted enones from the equivalent unsubstituted starting materials. Importantly, this outcome contrasts with the work of

Table 2 One-pot $\beta$-substitution of a range of enones with a simple Gilman cuprate

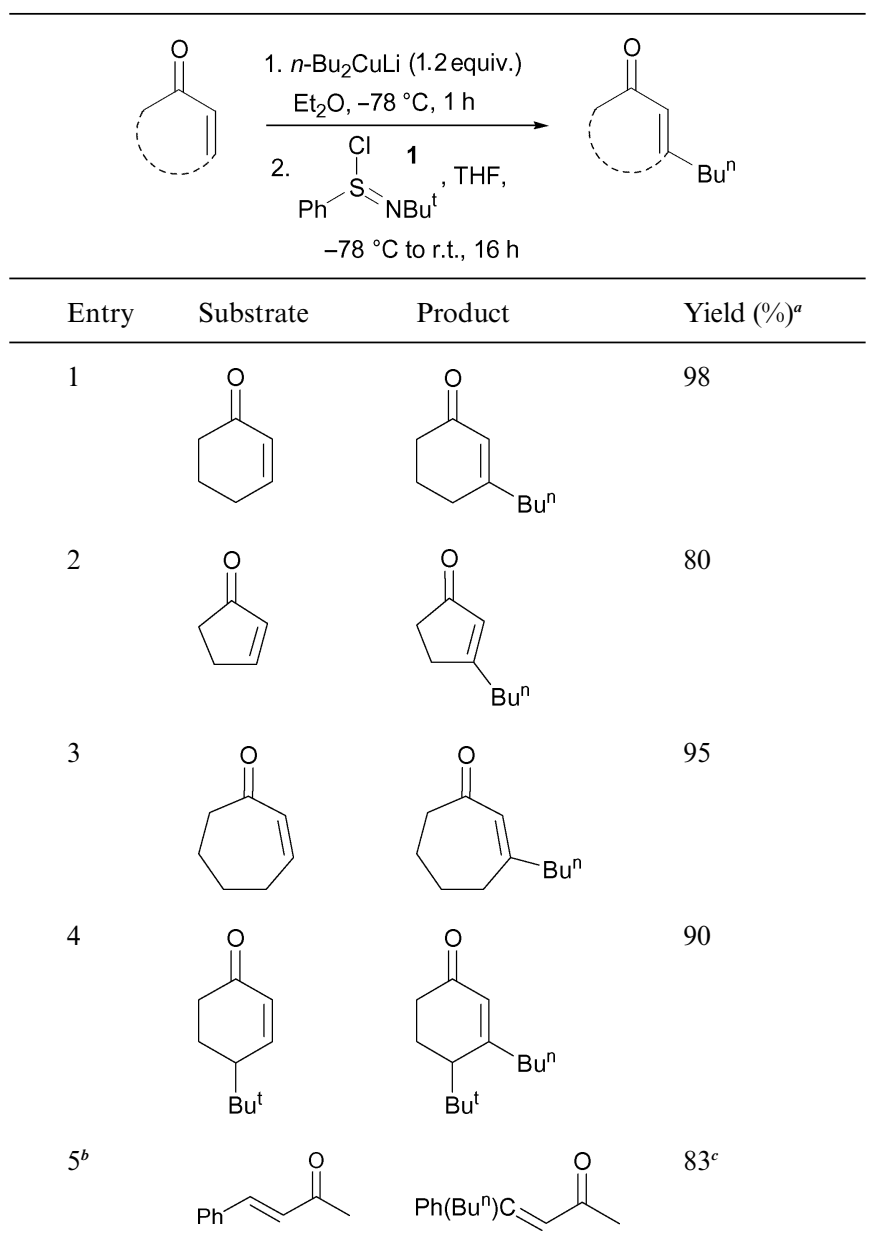

${ }^{a}$ Isolated yield. ${ }^{b}$ Initial reaction performed at $-20{ }^{\circ} \mathrm{C} .{ }^{c} Z: E 87: 13^{13}$
Matsuo and Aizawa, who found that use of a simple Gilman cuprate, followed by the addition of $\mathbf{1}$ in ether ( $c f$. in THF within our optimised system), only produced a low yield of the desired substituted enone product from cyclohex-2-enone $\left(\mathrm{Me}_{2} \mathrm{CuLi}\right.$, 3 equiv. 1; $27 \%$ yield). ${ }^{10}$

Following these successful initial optimisation studies, the generality and applicability of our developed method with alternative $\alpha, \beta$-unsaturated substrates was investigated using a Gilman cuprate. $\dagger$ As Table 2 illustrates, this technique provides good to excellent yields of $\beta$-substituted enones from all of the unsaturated starting materials employed. In this regard, enones of varied ring size (5-7) were applied without difficulty. Furthermore, a sixmembered ring substrate with a sterically demanding $t$-butyl group present in the 4-position also reacted very efficiently (Table 2, Entry 4). In addition, this method is not restricted to cyclic substrates, as can be seen from Entry 5, with a good 83\% yield being obtained from the acyclic substrate shown. Again, this shows some advantages over the recently published protocols, where the optimised conditions (with higher-order cuprates) delivered only low to moderate yields of substituted acyclic enones. ${ }^{10}$

Having demonstrated the use of various $\alpha, \beta$-unsaturated substrates, our attention turned to the delivery of alternative suitable lithium dialkylcuprates. Gratifyingly, the introduction of alternative alkyl groups was readily achieved, again in excellent yields. As illustrated in Table 3, delivery of methyl and $n$-octyl groups provided the product enones in 86 and $80 \%$ yield, respectively, with

Table 3 One-pot $\beta$-substitution of cyclohex-2-enone with alkyl and aryl units of simple Gilman cuprates

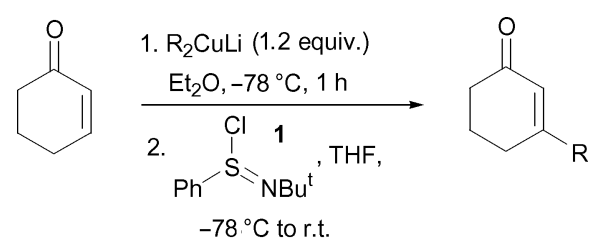

\begin{tabular}{lll}
\hline Entry & Product & Yield (\%) ${ }^{a}$ \\
\hline 1 & 98
\end{tabular}

2<smiles>CC1=CC(=O)CCC1</smiles>

3<smiles>CCOC1=CC(=O)CCC1</smiles>

4<smiles>O=C1C=C(c2ccccc2)CCC1</smiles>

86

80

84

${ }^{a}$ Isolated yield. 
the efficiency of the former process contrasting with the 27\% yield obtained with the same cuprate reagent and $\mathbf{1}$ under the recently published conditions. ${ }^{10}$ In addition and pleasingly, the conjugate delivery of a phenyl group was also highly effective (Table 3, Entry 4) demonstrating that this methodology is not solely limited to the introduction of alkyl groups.

Having established successful protocols with pre-formed Gilman reagents, we then further expanded our study and initiated investigations into alternative copper-mediated methods for 1,4attack on enones. In this regard, we firstly turned to copper iodide-catalysed conjugate additions with Grignard reagents. ${ }^{14}$ As shown in Table 4, the delivery of $\beta$-functionalised enones was, again, possible using this method, with primary, secondary, and tertiary alkyl groups all being delivered successfully. Whilst these copper-catalysed Grignard processes were marginally less efficient than the methods described above, good yields (73-74\%) of the functionalised enones were still obtained using this practicallyconvenient protocol.

It is widely recognised that the requirement for two equivalents of the nucleophilic component within dialkyl- or diarylcuprates lowers their overall effectiveness as reagents in organic synthesis, especially if the transferring alkyl or aryl unit is synthetically valuable. Despite the general effectiveness of the protocols developed here, the cuprates (and the copper-catalysed Grignard processes) employed, in conjunction with the sulfinimidoyl chloride $\mathbf{1}$, do require excesses of the nucleophilic agent. Based on this, we proceeded to investigate a number of alternative and potentially more preparatively economical organocuprate reagents, where only one equivalent of the transferring unit is employed. In this regard, use of a mono-organocuprate in dimethyl sulfide ${ }^{15}$ proceeded

Table 4 One-pot $\beta$-substitution of cyclohex-2-enone using coppercatalysed Grignard processesł

(1)

${ }^{a}$ Isolated yield. ${ }^{b}$ Only reacted at $-20{ }^{\circ} \mathrm{C}$ for $1 \mathrm{~h}$ prior to quench with $\mathbf{1}$.
Table 5 One-pot $\beta$-substitution of cyclohex-2-enone using more economical copper-based reagents with only one transferring unit.

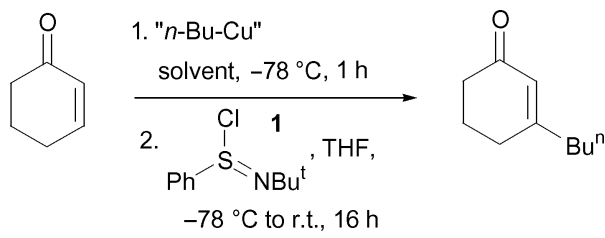

\begin{tabular}{llll}
\hline Entry & Reagent & Solvent $^{a}$ & ${\text { Yield }(\%)^{b}}^{b}$ \\
\hline 1 & $n$-BuCu.SMe & $\mathrm{Et}_{2} \mathrm{O}$ & 74 \\
2 & $n-\mathrm{BuCu}$ & $\mathrm{Et}_{2} \mathrm{O}$ & 77 \\
3 & $n-\mathrm{Bu}(2$-thienyl $) \mathrm{Cu}(\mathrm{CN}) \mathrm{Li}_{2}$ & $\mathrm{THF}$ & 76
\end{tabular}

${ }^{a}$ Solvent used for the addition of the copper reagent. ${ }^{b}$ Isolated yield.

effectively to deliver a $74 \%$ yield of the desired $\beta$-substituted enone product (Table 5, Entry 1). Indeed, as shown by Entry 2 in Table 5, for the delivery of such a simple alkyl group in our additionoxidation procedure, the sulfide additive was not required. Finally in this series, the popular thienylcuprates developed by Lipshutz, ${ }^{16}$ in which the 2-thienyl group is used as a non-transferable ligand within mixed higher-order cyanocuprates, were applied to our system with 1. Pleasingly, this also proved highly effective and produced a very good $76 \%$ yield of the desired enone product (Table 5, Entry 3). Interestingly, Matsuo and Aizawa have reported that, when using their established techniques, with ether as solvent for both the cuprate and sulfinimidoyl chloride, use of Lipshutztype higher-order cuprates bearing either a 2-thienyl or an $\mathrm{N}$ imidazolyl group only gave very low to moderate yields of the $\alpha, \beta$ unsaturated ketone product. In contrast and to complement the methods reported here, this previously published study shows how higher order dialkyl (or diaryl) cyanocuprates can be employed successfully in this addition-oxidation process, albeit with excesses of the transferring unit being required. ${ }^{10}$

In summary, we have developed a mild and practicallyconvenient one-pot conjugate addition-oxidation protocol, to directly produce $\beta$-substituted enones in a highly efficient manner. This methodology has proven to be effective with both cyclic and acyclic enones. Furthermore, the application of a series of individual organocuprate reagents has also been successfully demonstrated, to install primary, secondary, and tertiary alkyl units, as well as aryl moieties. Given all of these features, coupled with the ease of preparation and commercial availability of the oxidant, and linked with the simple experimental procedures developed, we feel that these techniques will be of value to the wider scientific community.

We thank the EPSRC for funding (G.J.T.), the C. K. Marr Trust for a Postgraduate Scholarship (C.M.P.), Pfizer Global Research and Development, Sandwich for generous funding of our research, and the EPSRC Mass Spectrometry Service, University of Wales, Swansea for analyses.

\section{Notes and references}

$\dagger$ Representative experimental procedure: to a slurry of $\mathrm{CuI}(229 \mathrm{mg}, 1.2$ $\mathrm{mmol})$ in $\mathrm{Et}_{2} \mathrm{O}(10 \mathrm{ml})$ cooled to $-78^{\circ} \mathrm{C}$, was added $n-\mathrm{BuLi}(2.5 \mathrm{M}, 0.96 \mathrm{ml}$, $2.4 \mathrm{mmol}$ ) dropwise. After stirring for $1 \mathrm{~h}$, cyclohexanone $(96.1 \mathrm{mg}, 1$ $\mathrm{mmol})$ in $\mathrm{Et}_{2} \mathrm{O}(2 \mathrm{ml})$ was carefully added. After stirring for a further 
$1 \mathrm{~h}, N$-tert-butylphenylsulfinimidoyl chloride (1) $(1077 \mathrm{mg}, 5 \mathrm{mmol})$ was added rapidly as a solution in THF $(3 \mathrm{ml})$. The reaction was then allowed to slowly warm to room temperature and stirring was continued for $16 \mathrm{~h}$. The reaction was then quenched with $2 \mathrm{M} \mathrm{HCl}(30 \mathrm{ml})$ and extracted with EtOAc $(3 \times 20 \mathrm{ml})$. The combined organics were then washed with brine $(30 \mathrm{ml})$ and dried over $\mathrm{MgSO}_{4}$. The crude residue was then carefully purified by silica chromatography eluting with ether-petroleum ether mixtures. The product, 3- $n$-butylcyclohex-2-en-1-one was obtained as a pale yellow oil $(150 \mathrm{mg}, 98 \%)$, with analysis identical to that described in the literature; ${ }^{17}$ IR (liq. film) $1670(\mathrm{C}=\mathrm{O}), 1624(\mathrm{C}=\mathrm{C}) \mathrm{cm}^{-1} ; \delta_{\mathrm{H}}(400 \mathrm{MHz}$, $\left.\mathrm{CDCl}_{3}\right): 5.87(\mathrm{~s}, 1 \mathrm{H}), 2.34-2.37(\mathrm{~m}, 2 \mathrm{H}), 2.27-2.30(\mathrm{~m}, 2 \mathrm{H}), 2.17-2.23(\mathrm{~m}$, $2 \mathrm{H}), 1.95-2.02(\mathrm{~m}, 2 \mathrm{H}), 1.19-1.51(\mathrm{~m}, 4 \mathrm{H}), 0.92(\mathrm{t}, J=7.2 \mathrm{~Hz}, 3 \mathrm{H})$. All other compounds exhibited satisfactory spectral and analytical data. $\$$ A solution of the Grignard reagent in ether was added over $15 \mathrm{~min}$ to an ether solution of $\mathrm{CuI}$ and enone at $-20^{\circ} \mathrm{C}$ and stirring was continued for $2 \mathrm{~h}$; the reaction mixture was then cooled to $-78^{\circ} \mathrm{C}$ and a solution of 1 in THF was then added and the mixture allowed to slowly warm to room temperature with continued stirring over $16 \mathrm{~h}$.

1 (a) H. J. Reich, J. M. Renga and I. L. Reich, J. Org. Chem., 1974, 39, 2133-2135; (b) H. J. Reich, J. M. Renga and I. L. Reich, J. Am. Chem. Soc., 1975, 102, 5434-5447.

2 B. M. Trost, Chem. Rev., 1978, 78, 363-382.

3 (a) E. Piers and I. Nagakura, J. Org. Chem., 1975, 40, 2694-2696; (b) E. Piers, K. F. Cheng and I. Nagakura, Can. J. Chem., 1982, 60, 1256-1263; (c) E. Piers, J. R. Grierson, C. K. Lau and I. Nagakura, Can. J. Chem., 1982, 60, 210-223.

4 K. C. Nicolaou, D. L. F. Gray, T. Montagnon and S. T. Harrison, Angew. Chem., Int. Ed., 2002, 41, 996-1000.

5 For the original preparation of $N$-tert-butylphenylsulfinimidoyl chloride, see: (a) L. N. Markovskii, T. N. Dubinina, E. S. Levchenko and A. V. Kirsanov, J. Org. Chem. USSR, 1973, 9, 1435-1439; for a more recent and practically-utilisable preparation, see: (b) J. Matsuo, D. Iida, K. Tatani and T. Mukaiyama, Bull. Chem. Soc. Jpn., 2002, 75, 223-234. 6 (a) T. Mukaiyama, J. Matsuo and M. Yanagisawa, Chem. Lett., 2000, 1072-1073; (b) T. Mukaiyama, J. Matsuo and H. Kitagawa, Chem. Lett., 2000, 1250-1251.

7 For reviews, see: (a) T. Mukaiyama, Angew. Chem., Int. Ed., 2004, 43, 5590-5614; (b) J. Matsuo, J. Synth. Org. Chem., Jpn., 2004, 62, 574-583. 8 J. Matsuo and Y. Aizawa, Tetrahedron Lett., 2005, 46, 407-410.

9 TCI Organic Chemicals, TCI Europe, B-2070 Zwijndrecht, Belgium. 10 J. Matsuo and Y. Aizawa, Chem. Commun., 2005, 2399-2401.

11 (a) J. A. Kozlowski, Comprehensive Organic Synthesis, ed. B. M. Trost and I. Fleming, Permagon, Oxford, 1991, vol. 4, pp. 169-198; (b) Organocopper Reagents, ed. R. J. K. Taylor, Oxford University Press, Oxford, 1994; (c) B. H. Lipshutz, R. S. Wilhelm and J. A. Kozlowski, Tetrahedron, 1984, 40, 5005-5038.

12 H. Gilman, R. G. Jones and L. A. Woods, J. Org. Chem., 1952, 17, $1630-1634$.

13 (a) G. Bartoli, E. Marcantoni, M. Petrini and L. Sambri, Chem. Eur. J., 1996, 2, 913-918; (b) R. K. Dieter, L. A. Silks, J. R. Fishpaugh and M. E. Kastner, J. Am. Chem. Soc., 1985, 107, 4679-4692; (c) L. M. Jackman and S. Sternhell, Application of Nuclear Magnetic Resonance Spectroscopy in Organic Chemistry, 2nd edn, Pergamon, London, 1969, pp. 221-224.

14 For a review, see: E. Endrik, Tetrahedron, 1984, 40, 641-657.

15 S. H. Bertz and G. Dabbagh, Tetrahedron, 1989, 45, 425-434.

16 (a) B. H. Lipshutz, J. A. Kozlowski, D. A. Parker, S. L. Nguyen and K. E. McCarthy, J. Organomet. Chem., 1985, 285, 437-447; (b) B. H. Lipshutz, D. A. Parker, J. A. Kozlowski and S. L. Nguyen, Tetrahedron Lett., 1984, 25, 5959-5962; (c) B. H. Lipshutz, M. Koerner and D. A. Parker, Tetrahedron Lett., 1987, 28, 945-948.

17 N. L. Hungerford and W. Kitching, J. Chem. Soc., Perkin Trans. 1, 1998, 1839-1858. 